Revista Portuguesa de Ciência Política | Portuguese Journal of Political Science ISSN: 1647-4090 | ISSN-e: 2184-2078 | 2018, Número 9, Páginas 147-151

DOI: $10.33167 / 2184-2078 . R P C P 2018.9 /$ pp.147-151

\title{
Lenine 2017
}

\author{
POR João Moreira * \\ * ICS - Instituto de Ciências Sociais, Portugal
}

Žižek, S. (2017). Lenine 2017 (1. ed.). Braga: Elsinore.

A mais recente obra de Slavoj Žižek enquadra-se no centenário da Revolução de Outubro, versando sobre aquele processo revolucionário - particularmente sobre o seu principal dirigente, Lenine, e a forma como este procurou contrariar o processo de burocratização do Partido Bolchevique e do Estado soviético.

Como pano de fundo não está nenhuma narrativa de matriz estalinista ou de matriz anticomunista - as mais comuns quando se assinalam os cem anos do assalto ao Palácio de Inverno. Pelo contrário, o filósofo esloveno - que tem em Sousa Dias um dos principais seguidores em Portugal - acaba por contrariar algumas ideais hegemónicas relativas à Revolução de Outubro, a Lenine e ao seu legado político.

Nesse quadro, por exemplo, é projetada ao longo do livro a luta do autor de Teses de Abril contra o desenvolvimento da burocracia e do chauvinismo russo - encabeçados por Estaline - no novo regime e no próprio Partido Comunista da União Soviética. Žižek vai mesmo mais longe afirmando a «visão» de Lenine relativa ao «Estado» e à «sociedade» no início da década de 1920 era "totalmente incompatível com a de Estaline» (Žižek, 2017, p. 66), nomeadamente no que dizia respeito à alegada teoria do socialismo num só país (Žižek, 2017, pp. 81-82). Aliás, seria o próprio Lenine a reconhecer no final da Guerra Civil que a sociedade soviética, acossada militar e economicamente, não ia em direção ao socialismo. Para o líder bolchevique, dada a conjuntura económica e internacional, a revolução deveria ter um «modesto projeto "realista"» que não se predispusesse aos "perigos de qualquer forma de "implantação direta do comunismo"», pois, nas suas palavras, a "pressa» seria «fatal, 
para o comunismo» (Žižek, 2017, p. 81). Ou seja, mais valia «menos, mas melhor» (Žižek, 2017, p. 315).

Outra tese central neste livro de Žižek - e que é igualmente contrariada pelas historiografias dominantes - é a heterodoxia teórica de Lenine. Segundo o filósofo esloveno, Lenine demonstrou-se um autor autónomo em relação a qualquer escolástica marxista. Disso eram exemplos a sua posição relativamente à autodeterminação dos povos - contrária, nomeadamente, à posição de Rosa Luxemburgo «que defendia que a atribuição de soberania completa a pequenas nações só devia ocorrer caso existisse a predominância de forças progressistas» (Žižek, 2017, p. 26) - e a sua opção pela «abertura parcial ao capitalismo» consagrada na Nova Política Económica (NEP) (Žižek, 2017, p. 346).

A elasticidade e a criatividade do pensamento teórico-político do principal dirigente da Revolução de Outubro entra, pois, em «contradição absoluta» com o «mito estalinista do leninismo». Para Žižek não há, portanto, dúvidas: «o "leninismo" é um conceito profundamente estalinista». Apesar de evocado «retroativamente pelo estalinismo», o leninismo pouco tem que ver com a "prática política» e a «ideologia» do «período de Lenine» (Žižek, 2017, pp. 98-99). Essa perspetiva tem, aliás, eco noutros autores. Como lembra também Rui Bebiano, os conceitos «marxismo-leninismo»e «leninismo» - inexistentes «em vida de Vladimir Ilitch» - são, de algum modo, inventados tendo em vista o combate político contra Trotsky (Bebiano, 2009, p. 25).

$\mathrm{O}$ autor esloveno também põe a nu outros lugares comuns (à esquerda e à direita) sobre a militância nos partidos comunistas tradicionais. Ora, se esta é (ou era) alegadamente constituída por indivíduos abnegados do ponto de vista da prática política, para Žižek, o mesmo não acontece no que diz respeito ao pensamento político. Segundo o autor, passa-se (ou passava-se) exatamente o oposto. A militância reveste-se, para o "verdadeiro estalinista», de «obediência a [...] mudanças arbitrárias» da direção e constitui-se como «derradeira prova da sua fidelidade» em relação ao partido. Exemplos disso foram os constantes zigue-zagues da direção do movimento comunista internacional e a sua réplica na base partidária: «primeiro os nossos inimigos são os sociais-democratas, depois temos de construir uma Frente Popular com eles; primeiro Hitler é o nosso inimigo derradeiro, depois fazemos um pacto com ele». A ausência «de argumentos que sustentem» tais orientações, mais do que «um sinal de fraqueza», é «uma prova de força» (Žižek, 2017, pp. 249-250) para aqueles homens e mulheres.

Quanto ao próprio processo revolucionário de 1917, Žižek observa-o — dado o seu isolamento internacional, as agressões económicas e militares sofridas e o seu pioneirismo - como um ato extremamente sensível ao erro. Na verdade nenhuma revolução de carácter socialista tinha alguma vez triunfado, quanto mais numa conjuntura tão desfavorável. Numa palavra, a Revolução Russa estava condenada ao fracasso tais eram as dificuldades iniciais. A Guerra Civil havia mesmo dizimado uma parte considerável daqueles que o Estado soviético dizia representar, a tal ponto de, segundo Žižek, no final da Guerra Civil o Estado se representar a ele próprio (Žižek, 2017, p. 97). É para essa hipótese que avança o historiador Moshe Lewin e que Žižek aproveita. Segundo o autor polaco, a «análise social» de Lenine não teve em conta «o 
aparelho de Estado enquanto elemento social distinto num país que tinha nacionalizado os principais setores económicos». Ora, para além do proletariado, do campesinato e da burguesia, haveria também que enquadrar o novo e extenso funcionalismo estatal. Ao não o fazerem, Lenine e os dirigentes bolcheviques não concluíram que, de algum modo, governavam num «vazio» («rapidamente preenchido»), e que a burocracia estava a tornar-se «a verdadeira base social do poder» (Žižek, 2017, pp. 98-99).

Ainda no que diz respeito aos pontos mais positivos deste livro deve ser referida a forma como Žižek dialoga com diversos autores mais ou menos populares no universo intelectual da Esquerda - Hegel, C.R. L. James, Trotsky, Lukács, Sartre, Badiou, Lewin ou Glick - problematizando e procurando respostas - muitas delas dolorosas para uma grande parte do marxismo.

Se a seu favor Žižek tem, por um lado, o facto de não tomar partido nem do estalinismo nem do anticomunismo - não tendo receio em utilizar os termos «estalinista» ou «burocracia» - por outro, enreda-se num tipo de texto por vezes hermético (talvez não seja de estranhar dada a sua formação em filosofia e em psicanálise). Assim, é frequente uma certa confusão de fontes e conceitos teóricos que dificulta a leitura - mesmo que atenta. Exemplo disso é quando Žižek afirma que Rosa Luxemburgo previu «a ascensão do estalinismo burocrático» — o qual, diga-se, é um conceito eventualmente redundante. A líder polaca previu, sim, a ascensão da burocracia (tal como Lenine, Trotsky e outros).

Também por isso, «os primeiros bolcheviques» não «teriam ficado chocados» com o atrofiamento da revolução. Basta ler textos da direção bolchevique de 1917 sobre as perspetivas da revolução europeia ou sobre as consequências do isolamento internacional da Revolução. Nesse aspeto, o «terror estalinista» não foi «a derradeira consequência» da política bolchevique. Pelo contrário, foi consequência de um país devastado pelas guerras e, simultaneamente, isolado internacionalmente (Žižek, 2017, p. 65).

Ao contrário do que afirma Žižek, partindo de uma perspetiva histórica, «a solução específica de Lenin» não «falhou» (Žižek, 2017, p. 22). O que alegadamente falhou foi a direção da social-democracia europeia que, a partir de 1914, se aliou aos regimes autoritários que visava derrubar e, mais do que isso, deixou isolada a Revolução Russa; a revolução internacional, que iria em auxílio do processo revolucionário russo, foi afogada não apenas pelos regimes políticos vigentes mas também pela própria social-democracia europeia.

Deve ainda ser referido o facto de ser patente alguma «desorientação» teórica de Žižek em alguns conceitos redundantes ou paradoxais por ele utilizados, como «estalinismo burocrático», «revolucionário estalinista» (Žižek, 2017, p. 354), «socialismo estatal» (Žižek, 2017, p. 96) ou mesmo «evento leninista» (Žižek, 2017, p. 21). Este último é mais grave pois confunde um processo histórico-social com um dos seus protagonistas. A formação académica de Žižek promove alguns equívocos que não devem ser desculpáveis. Se a formação do autor é em filosofia, é sabido igualmente que aquele é um intelectual que se afirma marxista e, por isso, deveria manejar melhor a ampla rede conceitual promovida pelo marxismo. 
Por fim, Žižek volta a equivocar-se ao subscrever a análise de Sartre sobre o alegado «socialismo dos campos de concentração» e a sua pergunta "como pudera a sociedade soviética sentá-lo num trono e mantê-lo lá durante um quarto de século?» (Žižek, 2017, p. 13). Se a primeira expressão corresponde a uma contradição nos termos, a pergunta não compreende nenhuma análise sistemática e sistémica do regime de Estaline - já realizada por autores tão diferentes como Lukács, Trotsky ou mesmo Hannah Arendt (para não referir os mais recentes). Ora, a explicação da vida sociopolítica não resulta da culpabilização de milhões de pessoas. Não deveria Sartre ter questionado a sua perigosa ligação ideológica a Estaline? A citação de Sartre é ainda mais incompreensível para um autor marxista mas também tendo em conta que tanto Lukács como Trotsky e parte das suas análises sobre a URSS da década de 1930 são referidas mais adiante no livro. Aliás, Žižek oferece ao leitor a hipótese sugerida por Glick (influenciado por C. R. L. James) na qual Estaline surge como mediação entre a revolução e a contra-revolução. A título de exemplo, tal como o papado não era o objeto final do "primeiros cristãos revolucionários», mas uma «mediação à volta da qual as forças sociais governantes se agregaram para subjugar a busca pela universalidade pela parte das massas cristãs», também Estaline e a burocracia constituíram também uma mediação na União Soviética (Termidor da Revolução de Outubro).

Qual, então, o programa de Žižek? Qual a esquerda de Žižek? Se não se enquadra no «cinismo resignado» associado ao ex-PCUS (Žižek, 2017, p. 15) e se reclama um Programa Mínimo e um Programa Máximo - pois afirma «a necessidade de uma mudança universal radical tem de surgir através da mediação com exigências particulares» —, qual a posição política de Žižek? O autor dá algumas pistas: segundo este, «a ilusão de 1917 de que os problemas mais prementes que a Rússia enfrentava (paz, distribuição de terra, etc.) podiam ser resolvidos por meios parlamentares "legais" é igual à ilusão contemporânea de que, por exemplo, a ameaça ecológica pode ser evitada estendendo a lógica de mercado à ecologia (obrigando os principais poluidores a pagar pelos danos que causam, etc.)» (Žižek, 2017, p. 83). Colocando-se, portanto, no espectro anticapitalista, o filósofo afirma ser necessária «uma cisão clara da[s] experiência[s]» da Esquerda no século xx: quer as associadas ao estalinismo, quer as associadas ao reformismo social-democrata. Žižek não aceita que a Esquerda, sem «projeto radical», se limite a «bombardear o Estado com exigências de expansão do Estado social, sabendo perfeitamente que o Estado não as poderá satisfazer» (Žižek, 2017, p. 41). Mais do que criticar a «incapacidade» do Estado social - no contexto político-partidário contemporâneo este espaço está já reservado à direita - a Esquerda deve apresentar «o seu próprio projeto positivo para lá dos limites do conceito social-democrata de Estado social». Caso contrário, será o «populismo de direita»a ganhar a «reação» à crítica ao Estado social e - não é de excluir esta hipótese - a ver-se aliado à esquerda que mais não exige do que «nações-Estado soberanas fortes» (Žižek, 2017, pp. 41-42).

É para Žižek, portanto, necessário que a Esquerda volte ao início. É preciso, pois, «repetir Lenine» - ainda que não o que ele fez, «mas o que [...] não conseguiu fazer, as suas oportunidades perdidas» (Žižek, 2017, p. 22). Assim, e utilizando a famosa 
passagem de Samuel Beckett, Žižek adverte a Esquerda: «Tenta outra vez. Falha outra vez. Falha melhor» (Žižek, 2017, pp. 39-40).

\section{Referências}

Žižek, S. (2017). Lenine 2017 (1. ${ }^{a}$ ed.). Braga: Elsinore.

Bebiano, R. (2009). Outubro. Coimbra: Angelus Novus. 